\title{
Shear rate effect on the residual strength characteristics of saturated loess in naturally drained ring shear tests
}

\author{
Baoqin Lian ${ }^{1,2}$, Xingang Wang ${ }^{1}$, Jianbing Peng ${ }^{2}$, and Qiangbing Huang ${ }^{2}$ \\ ${ }^{1}$ State Key Laboratory of Continental Dynamics, Department of Geology, Northwest University, Xi' an 710069, China \\ ${ }^{2}$ College of Geological Engineering and Surveying, Chang' an University, Key Laboratory of Western China Mineral \\ Resources and Geological Engineering, Xi'an 710054, China
}

Correspondence: Xingang Wang (xgwang@nwu.edu.cn) and Jianbing Peng (dicexy1@gmail.com)

Received: 13 May 2019 - Discussion started: 23 September 2019

Revised: 30 March 2020 - Accepted: 14 April 2020 - Published: 28 October 2020

\begin{abstract}
Residual shear strength of soils is an important soil parameter for assessing the stability of landslides. To investigate the effect of the shear rate on the residual shear strength of loessic soils, a series of naturally drained ring shear tests were carried out on loess from three landslides at two shear rates $\left(0.1\right.$ and $\left.1 \mathrm{~mm} \mathrm{~min}^{-1}\right)$. Experimental results showed that the shear displacement to achieve the residual stage for specimens with higher shear rate was greater than that of the lower rate; both the peak and residual friction coefficient became smaller with increase in shear rate for each sample; at two shear rates, the residual friction coefficients for all specimens under the lower normal stress were greater than those under the higher normal stress. Moreover, specimens with almost the same low fraction of clay (CF) showed a similar shear rate effect on the residual friction coefficient, with normal stress increasing, whereas specimens with high CF (24\%) showed a contrasting tendency, indicating that such an effect is closely associated with CF. The test results revealed that the difference in the residual friction angle $\phi_{\mathrm{r}}$ at the two shear rates, $\phi_{\mathrm{r}}(1)-\phi_{\mathrm{r}}(0.1)$ under each normal stress level are either positive or negative values, of which the maximum magnitude is about $0.8^{\circ}$. However, the difference $\phi_{\mathrm{r}}(1)-\phi_{\mathrm{r}}(0.1)$ determined under all normal stress levels was negative, which indicates that the residual shear parameters reduced with the increasing of the shear rate in the loess area. Such a negative shear rate effect on loess could be attributed to a greater ability of clay particles in specimens to restore broken bonds at low shear rates.
\end{abstract}

\section{Introduction}

Residual shear strength of soil is of great significance for evaluating the stability of the slip surface of first-time landslides as well as reactivated landslides (Bishop et al., 1971; Mesri and Shahien, 2003; Tiwari and Latha, 2019; Li et al., 2017). The residual strength of soils is defined as the minimum constant value of strength along the slip plane, in which the soil particles are reoriented and subjected to sufficiently large displacements in relatively low shear rate (Skempton, 1985).

Numerical studies have been done to assess the residual strength through laboratory tests using ring shear tests and reversal direct shear tests (Vithana et al., 2012; Summa et al., 2018, 2010; Moeyersons et al., 2008; Chen and Liu, 2013). It is a generally accepted fact that the measurement of the residual strength is most preferably done with a ring shear test since it allows the soil specimen to be sheared at unlimited displacement, which can simulate the field conditions more accurately (Sassa et al., 2004; Tiwari and Marui, 2005; Lupini et al., 1981; Bhat, 2013). Until now, great efforts have been made to study the shear rate effect on the minimum value of clay or sand strength at residual states $(\mathrm{Li}$ et al., 2017; Tika and Hutchinson, 1999; Suzuki et al., 2007; Grelle and Guadagno, 2010; Lemos, 1985; Tika, 1999; Morgenstern and Hungr, 1984). As a result, the residual strength of clay or sand under the effect of shear rate has been made relatively clear. However, compared with the results of tests on clay or sand, understanding of the shear characteristics of silty soil, such as loess, is not yet complete. As pointed out by Ding (2016), some drained ring shear tests have concluded 
that the increase in shear rate causes the residual strength of loess to increase. In contrast, Kimura et al. (2014) reported that the residual strength of Malan loess decreases with the increase in shear rate. Furthermore, Wang et al. (2015) found that the effect of shear rate on the residual strength of loess is closely associated with the normal stress levels, and the change in residual strength of loess samples under high normal stress levels is small in ring shear tests.

Therefore, some inconsistent or even opposite results have been reported in the ring shear tests on loess above, which may be attributed to the differences in the grain size distribution and mineral composition of the different material tested in previous studies (Ajmera et al., 2012). Particularly, this discrepancy may be due to the difference in quantity and mineralogy of clay fraction (Nakamura et al., 2010; Li et al., 2013). Therefore, the previous studies on the effect of shear rate on residual strength of loess implied that there is still a lack of experimental data on this topic. From the above investigations, it can be concluded that the effect of the shear rate on the residual strength of the loess is not fully understood and needs further scrutiny. Moreover, it should be noted that the residual strength parameters (friction angle) obtained from using different shear rates may be adopted to provide a guide for designing some precision engineering, which requires high accuracy of the design parameters; thus, the effect of the shear rate on the residual strength of soils should be fully investigated to determine the parameters with high reliability. In addition, residual strength parameters of soil play a key role in assessing the stability analysis of landslides (Xu et al., 2018; Wesley, 2011). Therefore, accurate determination of the residual strength parameters and their dependence on the shear rate may affect the stability evaluation of landslides. Thus, it is necessary to study the change in residual strength of loess with shear rate in order to have a good understanding of the suitable approach for the residual strength parameter measurement.

Against this backdrop, to clarify the residual shear characteristics of loess under the effect of the shear rate, a series of naturally drained ring shear tests were conducted on loess obtained from three landslides on the Loess Plateau in China at two shear rates $\left(0.1\right.$ and $\left.1 \mathrm{~mm} \mathrm{~min}^{-1}\right)$. The residual shear characteristics of loess at the residual state was examined. Considering that shear strength of loess reduces with moisture content (Picarelli, 2010; Zhang et al., 2009; Dijkstra et al., 1994), ring shear tests were conducted on saturated loess samples corresponding to the worst condition in field engineering. Furthermore, this study investigated the change in the residual strength parameters of loess at different shear rates and the relationship between the residual strength parameters with the normal stress in naturally drained ring shear tests as well.

\section{Geological setting of landslide sites}

Soil samples from three landslides in the northwest of China were selected in this study. Soil samples used for the ring shear tests and index measuring tests predominantly consist of loess deposits and were collected in a disturbed condition. For convenience, the names of landslide sites were abbreviated as DJG, YDG and DBZ. Figure 1 shows the study sites and some views of the landslides.

\subsection{Dingjiagou landslide (DJG)}

The DJG landslide, located at the mouth of Dingjia Gully in Yan'an of China, is geologically composed of upper loess and lower sand shale in the Triassic Yanchang formation (She, 2015). The dustpan-shaped landslide is inclined to the east, with its inclination $75.85^{\circ}$. The landslide is $350 \mathrm{~m}$ in width, $180 \mathrm{~m}$ in length and $70 \mathrm{~m}$ in elevation. The average thickness of the slip mass is around $20 \mathrm{~m}$, and the volume of the landslide totaled approximately $105 \times 10^{4} \mathrm{~m}^{3}$. The slip mass is mainly constituted of loess, whereas the sliding bed consists of sand shale in the Yanchang formation. The thickness of the sliding zone varied from 30 to $50 \mathrm{~cm}$. The front lateral region of the main slide section of the DJG landslide, where the sampling was performed, was found to be silty clay.

\subsection{Yandonggou landslide (YDG)}

The YDG landslide is located in the town of Qiaogou in Yan'an, in Shaanxi province of China. The top and the toe altitude of the landslide are about 1165 and $1110 \mathrm{~m}$ above the sea level, with the height difference between the toe and the top of landslide about $55 \mathrm{~m}$. The slides have well-developed boundaries with the main sliding direction of $240^{\circ}$ and slope angle of $30^{\circ}$. From the landslides profile, the sliding masses from top to bottom were classified by late Pleistocene $\left(\mathrm{Q}_{3}\right)$ loess, Lishi $\left(\mathrm{Q}_{2}\right)$ loess and clay soil, respectively (Zhang et al., 2006). Multiple landslides had occurred in this site, and the soil samples used in this study were collected from $\mathrm{Q}_{2}$ loess stratum within the slide ranged from 4.5 to $18 \mathrm{~m}$ in height.

\subsection{Dabuzi landslide (DBZ)}

The DBZ landslide located in the middle part of Shaanxi province (about $34^{\circ} 28^{\prime} 48^{\prime \prime} \mathrm{N}, 108^{\circ} 51^{\prime} 36^{\prime \prime} \mathrm{E}$ ), China, which is a semiarid zone dominated by loessic geology (Yan et al., 2015). In this region, the investigated site is classified as a typical loess tableland with Quaternary stratum (Ma et al., 2019). The sedimentary loesses in this area are grayyellow, and the exposure stratum in this area has been divided into two stratigraphic units, namely the upper Malan $\left(\mathrm{Q}_{3}\right)$ loess and the lower Lishi $\left(\mathrm{Q}_{2}\right)$ loess, of which the $\mathrm{Q}_{3}$ loess is younger. The $\mathrm{Q}_{3}$ loess is closest to the surface and is up to approximately $12 \mathrm{~m}$ thick, while the thickness of $\mathrm{Q}_{2}$ loess may 


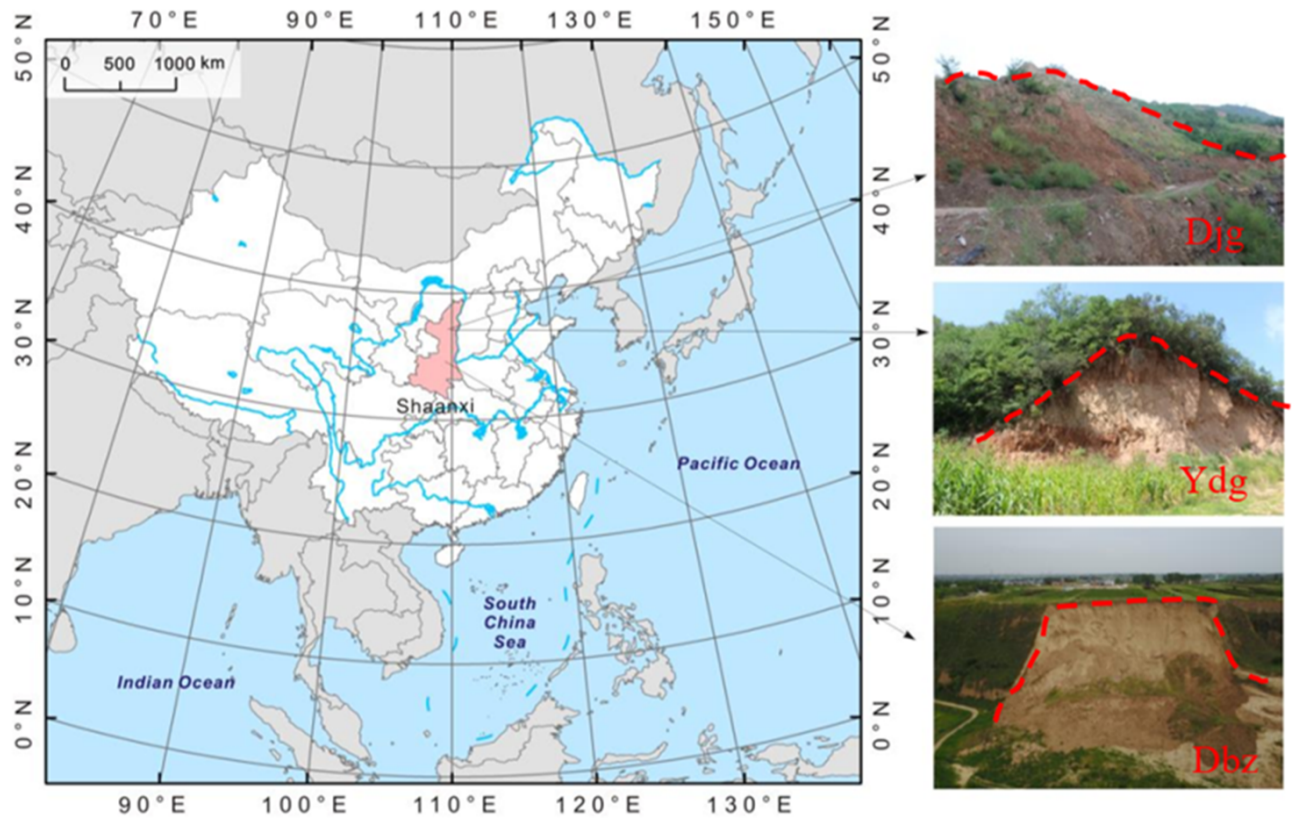

Figure 1. Location of study sites and some views of landslides (after Hu et al., 2018). Notes: dashed red lines in Fig. 1 represent the landslide boundary.

reach an upper limit of about $50 \mathrm{~m}$ (Leng et al., 2018). The loesses in this area have well-developed vertical joints (Sun et al., 2009). The travel distance and the maximum width of the slip mass are roughly estimated to be 122 and $133 \mathrm{~m}$, respectively. The armchair-shaped landslide shows an apparent sliding plane, with an area of approximately $15660 \mathrm{~m}^{2}$ and about $66.25 \mathrm{~m}$ maximum difference in elevation. The main direction of this landslide is approximately $355^{\circ}$. The exposed side scarp of the landslide, where the sampling was done, was found to be entirely in the $\mathrm{Q}_{2}$ loess stratum.

\section{Experimental scheme}

\subsection{Testing sample}

The fact that the residual shear strength is independent of the stress history has been reported by many researchers (Bishop et al., 1971; Stark et al., 2005; Vithana et al., 2012). Thus, disturbed loess samples from each landslide weighing about $25 \mathrm{~kg}$ were collected to investigate the residual shear strength.

The soil samples were air-dried and then crushed with a mortar and pestle as it has been reported that crushing samples was suitable to determine the residual strength of the remolded soils (Stark et al., 2005). It was found that small lumps may exist in air-dried samples, which may be too big for the cell, so lumps were crushed in order to make the samples uniform. This should be done with care so as not to destroy silt-dominated loess. After that, soil samples were processed through a $0.5 \mathrm{~mm}$ sieve. Distilled water was then added to the soil samples until saturated water content was obtained. The physical parameters such as natural moisture content (in situ moisture content), specific gravity, bulk density, plastic limit and liquid limit were determined in accordance with the Chinese National Standards (CNS) GB/T 50123-1999 (standards for soil test methods; SAC, 1999), but clay size was defined to be less than $2 \mu \mathrm{m}$ following ASTM D422 (ASTM, 2007). Each soil sample was separated into clay $(<0.002 \mathrm{~mm})$, silt $(0.002-0.075 \mathrm{~mm})$ and sand $(0.075$ $0.5 \mathrm{~mm}$ ) fractions. The physical indexes of the soil are listed in Table 1.

The grain size distribution of soil was measured using a Bettersize 2000 (Dandong Bettersize Instruments Corporation, Dandong, China) laser particle size analyzer. The sieved soil samples were used to determine particle size distribution. In this study, soil samples were treated with sodium hexaphosphate, serving as a dispersant, to disaggregate the bond between the particles. The particle size distribution curves of soils are shown in Fig. 2. The results show that the clay fraction in DJG landslide soil $(24 \%)$ is more than 2 times that of YDG (9\%) and DBZ (9.1\%). Furthermore, the particle size analysis illustrated that the percentage of silt-sized soil in the three landslides ranged from $75.66 \%$ to $87.4 \%$. In addition, YDG landslide soil consists of the greatest percentage of sand, reaching up to $10.55 \%$ (Table 2 and Fig. 2).

\subsection{Testing apparatus}

An advanced ring shear apparatus (SRS-150), the Bromheadtype ring shear apparatus manufactured by GCTS (Arizona, 
Table 1. Physical parameters of slip zone loess.

\begin{tabular}{lrrrrrrrrrrr}
\hline Sites & \multirow{2}{*}{$\rho_{\mathrm{d}}$} & $w$ & $\rho$ & $G_{\mathrm{S}}$ & $W_{\mathrm{L}}$ & $W_{\mathrm{p}}$ & \multicolumn{3}{c}{ Grain size fractions $(\%)$} \\
\cline { 7 - 10 } & & & & & & & $<0.002 \mathrm{~mm}$ & $0.002-0.005 \mathrm{~mm}$ & $0.005-0.075 \mathrm{~mm}$ & $0.075-0.5 \mathrm{~mm}$ \\
\hline DJG & 1.74 & 19.5 & 2.08 & 2.65 & 36 & 20 & 24 & 11.48 & 64.18 & 0.34 \\
YDG & 1.47 & 18 & 1.74 & 2.71 & 33 & 19 & 9 & 5.28 & 75.17 & 10.55 \\
DBZ & 1.48 & 16 & 1.72 & 2.70 & 32 & 21 & 9.1 & 6.4 & 81 & 3.5 \\
\hline
\end{tabular}

Notes: $\rho_{\mathrm{d}}=\operatorname{dry}$ density $\left(\mathrm{g} \mathrm{cm}^{-3}\right) ; w=$ moisture content $(\%) ; \rho=$ bulk density $\left(\mathrm{g} \mathrm{cm}^{-3}\right) ; G_{\mathrm{S}}=$ specific gravity; $W_{\mathrm{L}}=$ liquid limit $(\%) ; W_{\mathrm{p}}=$ plastic limit $(\%)$.

Table 2. Residual shear strength parameter of landslide soils.

\begin{tabular}{|c|c|c|c|c|c|c|c|c|}
\hline \multirow[t]{3}{*}{ No. } & \multirow[t]{3}{*}{ Sample } & \multirow{3}{*}{$\begin{array}{c}\text { Normal stress } \\
\left(\mathrm{kN} \mathrm{m}^{-2}\right)\end{array}$} & \multicolumn{4}{|c|}{ Residual strength parameter } & \multirow{2}{*}{\multicolumn{2}{|c|}{$\begin{array}{l}\text { Difference in parameter } \\
\phi_{\mathrm{r}(1)}-\phi_{\mathrm{r}(0.1)}\left(^{\circ}\right)\end{array}$}} \\
\hline & & & \multicolumn{2}{|c|}{$\phi_{\mathrm{r}(0.1)}\left({ }^{\circ}\right)$} & \multicolumn{2}{|c|}{$\phi_{\mathrm{r}(1)}\left({ }^{\circ}\right)$} & & \\
\hline & & & Under each $\sigma_{n}$ & Under all $\sigma_{n}$ & Under each $\sigma_{n}$ & Under all $\sigma_{n}$ & Under each $\sigma_{n}$ & Under all $\sigma_{n}$ \\
\hline \multirow{4}{*}{1} & \multirow{4}{*}{ DJG } & 100 & 16.699 & \multirow{4}{*}{15.003} & 16.699 & \multirow{4}{*}{14.090} & 0 & \multirow{4}{*}{-0.913} \\
\hline & & 200 & 15.563 & & 15.642 & & 0.079 & \\
\hline & & 300 & 15.110 & & 14.216 & & -0.894 & \\
\hline & & 400 & 14.708 & & 13.496 & & -1.212 & \\
\hline \multirow{4}{*}{2} & \multirow{4}{*}{ YDG } & 100 & 29.683 & \multirow{4}{*}{27.954} & 27.474 & \multirow{4}{*}{26.778} & -2.209 & \multirow{4}{*}{-1.176} \\
\hline & & 200 & 29.466 & & 27.248 & & -2.218 & \\
\hline & & 300 & 27.923 & & 26.870 & & -1.053 & \\
\hline & & 400 & 27.474 & & 26.565 & & -0.909 & \\
\hline \multirow{4}{*}{3} & \multirow{4}{*}{ DBZ } & 100 & 38.660 & \multirow{4}{*}{32.822} & 37.235 & \multirow{4}{*}{32.293} & -1.425 & \multirow{4}{*}{-0.529} \\
\hline & & 200 & 34.019 & & 33.425 & & -0.594 & \\
\hline & & 300 & 33.024 & & 32.619 & & -0.405 & \\
\hline & & 400 & 32.005 & & 31.487 & & -0.518 & \\
\hline
\end{tabular}

USA), was adopted in ring shear tests, and photos of the apparatus are shown in Fig. 3. The apparatus consists mainly of a shear box with an outer diameter of $150 \mathrm{~mm}$, an inner diameter of $100 \mathrm{~mm}$ and a maximal sample height of $250 \mathrm{~mm}$. The shearing box consists of the upper shear box and the lower shear box. In the shearing process, the upper shear box keeps still, while the lower one rotates. The apparatus, which provides an effective specimen area of $98 \mathrm{~cm}^{2}$, is capable of shearing the specimen for large displacements. The annular specimen is confined by inside and outside metal rings. Moreover, the specimen is confined by bottom annular porous plates and top annular porous plates which have sharp-edged radial metal fins which protrude vertically into the top and bottom of the specimen during the shearing process. Two annual porous plates were used to provide drainage conditions in the test following previous research (Stark and Vettel, 1992). The normal stress, shear strength and shear displacement can be monitored by computer during the shearing process. The measurement features of the ring shear apparatus employed in this study are described as follows: shear rate range from 0.001 to $360^{\circ} \mathrm{min}^{-1}, 10 \mathrm{kN}$ axial load capacity, $300 \mathrm{Nm}$ continuous torque capacity, maximum normal stress of $1000 \mathrm{kN} \mathrm{m}^{-2}$.

\subsection{Testing procedure}

This study was comprised of three groups of test results in which 24 remolded saturated loess samples were sheared with normal stress ranging from 100 to $400 \mathrm{kN} \mathrm{m}^{-2}$ at two shear rates. In the present study, reconstituted samples of the $<0.5 \mathrm{~mm}$ soil fractions were prepared for the shear tests as it was reported that the residual strength of the soil was unaffected by its initial structure (Vithana et al., 2012; Bishop et al., 1971). Consolidated drained (CD) tests with single-stage shear were performed. Here, the single-stage shear means shearing the sample under effective pressure or stress conditions after the consolidation of the sample. Specimens were 

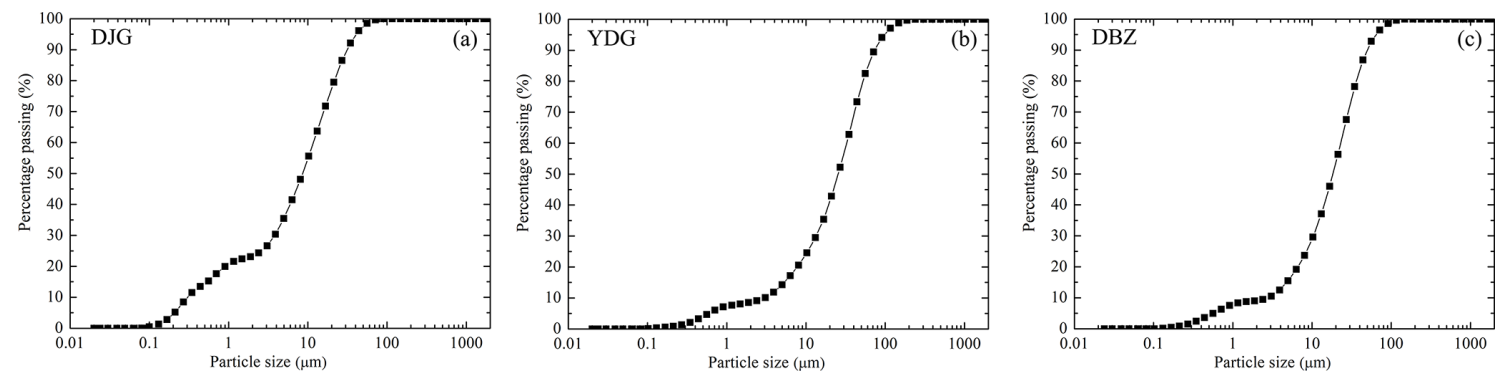

Figure 2. Particle size distribution curves. (a) Particle size distribution curve of soil obtained from DJG. (b) Particle size distribution curve of soil obtained from YDG. (c) Particle size distribution curve of soil obtained from DBZ.
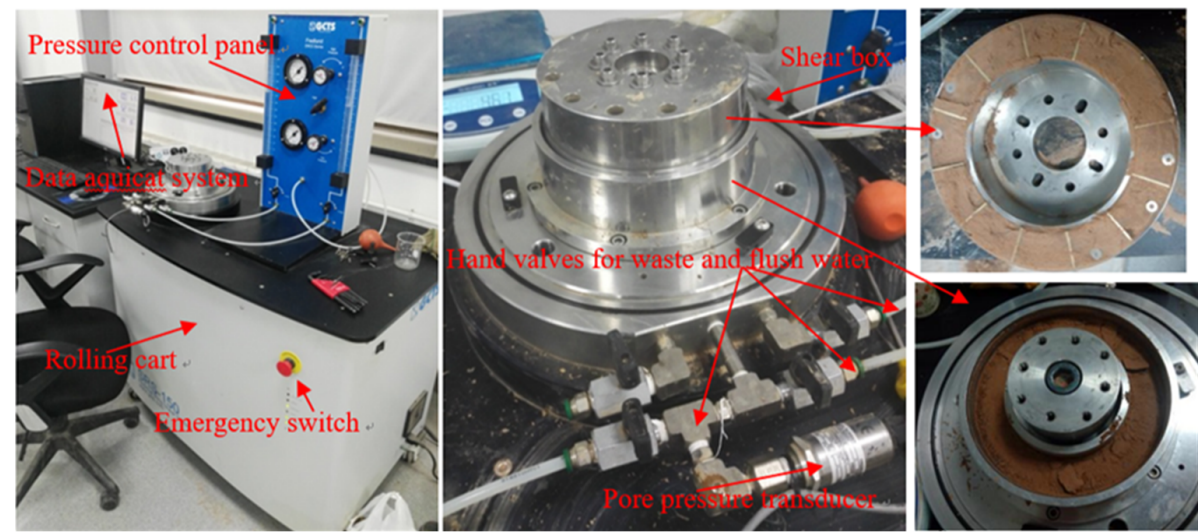

Figure 3. Ring shear apparatus (SRS-150).

first prepared by adding distilled water to the air-dried soil until the saturated moisture contents were obtained. Then, specimens were kept in a sealed container for at least 1 week to fully hydrate. Afterwards, specimens are reconstituted in the ring-shaped chamber of the apparatus by compaction. During the compaction process, samples were divided into five equal parts, and each part was poured into the shear box and compacted. Samples with a height of $2.5 \mathrm{~cm}$ in this study were prepared in five layers of equal height to achieve the required density. The specimen was then consolidated under a specific effective normal stress in a range of 100 to $400 \mathrm{kN} \mathrm{m}^{-2}$ until consolidation was achieved. In this study, consolidation was completed when the consolidation deformation was smaller than $0.01 \mathrm{~mm}$ within $24 \mathrm{~h}$ (Kramer et al., 1999; Shinohara and Golman, 2002). In ring shear tests, the normal stress during the shearing was the same as during the consolidation stage. Shear strength of the loess specimen was recorded at intervals of $1 \mathrm{~s}$ before the peak shear strength; after the peak, the sampling rate was increased to $1 \mathrm{~min}$.

In this study, ring shear tests were performed in a single stage under naturally drained conditions, and the samples were subjected to shearing until the residual state was achieved. Following Bromhead (1992), the residual state was defined as being when a constant shear stress is obtained for more than $30 \mathrm{~min}$. The drained condition of the shear- ing process is provided by two porous stones attached on the top and the bottom platen of the specimen container. As for soil specimens with low permeability, the rate of excess pore pressure generation in the shear box may exceeded that of pore pressure dissipation; this type of condition is identified as a naturally drained condition in previous studies (Okada et al., 2004). Furthermore, Tiwari (2000) asserted that it was acceptable to use a shear rate below $1.1 \mathrm{~mm} \mathrm{~min}^{-1}$ to simulate the field naturally drained condition. Thus, shear rates of 0.1 and $1 \mathrm{~mm} \mathrm{~min}^{-1}$ were used in this study to simulate the naturally drained condition of the slip zone soils.

\section{Results and discussion}

A total of 24 specimens were tested to investigate the residual shear characteristics of the saturated loess in the ring shear apparatus. Residual shear strength of the loess was determined following the research conducted by Bromhead (1992), who pointed out that the residual stage is attained if a constant shear stress is measured for more than $30 \mathrm{~min}$. Test results are shown in this section. 


\subsection{Shear behavior}

Figures $4 \mathrm{a}-6 \mathrm{a}$ show the typical shear characteristics of the loess (shear rate of 0.1 and $1 \mathrm{~mm} \mathrm{~min}^{-1}$ ) obtained from three different locations where the shear stress is plotted against the shear displacement. It is a widely accepted fact that normal stress has an effect on the shear behavior of the soil (Wang et al., 2019; Eid, 2014; Kimura et al., 2015; Stark et al., 2005; Eid et al., 2019) and thus the shear behavior of samples at the peak and residual stages, where the determined peak friction coefficient as well as residual friction coefficient is plotted in Figs. 4b-6b against the corresponding effective normal stresses as well. The friction coefficient is defined as the shear stress divided by the effective normal stress.

Figures $4 \mathrm{a}-6 \mathrm{a}$ demonstrate that shear stress increases dramatically within small shear displacement and then reduces with shear displacement until residual conditions were achieved at large displacements. Furthermore, it is obvious that the peak strength and the residual strength of samples with a high shear rate (shear rate equal to $1 \mathrm{~mm} \mathrm{~min}^{-1}$ ) are almost smaller than that of the samples with a low shear rate (shear rate equal to $0.1 \mathrm{~mm} \mathrm{~min}^{-1}$ ). It can be found that shear displacement to achieve the residual stage for specimens with a high shear rate is greater than that of the low rate. For example, the minimum shear displacements for attaining a residual condition for DJG specimens with low and high shear rate were about 360 and $650 \mathrm{~mm}$, respectively. Under the shear rate of 0.1 and $1 \mathrm{~mm} \mathrm{~min}^{-1}$, YDG specimens need approximately 80 and $1400 \mathrm{~mm}$ displacement to achieve the residual stage. However, DBZ specimens require about 40 and $60 \mathrm{~mm}$ displacement to reach a residual condition for low and high shear rate, respectively.

In Figs. 4a-6a, a clear drop can be seen at any normal stress for specimens obtained from all sites. During shearing, as reported by Terzaghi et al. (1996), strain softening exhibits a dilative behavior for soils. It is seen that the shear behavior is nonlinear against the shear displacement. The loess in DJG, YDG and DBZ exhibited a typical shear stress and shear strain relationship, i.e., the strain-softening behavior for a given shear rate (Figs. 4a-6a). As seen in Figs. 4a$6 a$, the lower shear rate results in a more obvious dilation effect during the shearing process with a specific normal stress. It is obvious that DJG specimens showed greater postpeak drop than that of YDG and DBZ specimens. For example, at the normal stress of $100 \mathrm{kN} \mathrm{m}^{-2}$, DJG samples show an approximately $47.3 \%$ and $36.8 \%$ decrease from the peak friction coefficient to the residual friction coefficient at low and high shear rates (Fig. 4b), respectively, which is greater than in the YDG samples (about $9.8 \%$ and $10.3 \%$; Fig. 5b) and DBZ samples (about $2.4 \%$ and $3.2 \%$; Fig. 6b). In DJG samples, an obvious slickenside was observed on the shear surface (Fig. 7). This phenomenon indicates a high degree of reorientation of platy clay minerals parallel to the direction of shearing. In Figs. $4 b-6 b$, on average, it was found that the decrease in the friction coefficient from the peak strength in the DJG sample is almost $18.1 \%$ and $21.3 \%$ for the sample consolidated at normal stress of $400 \mathrm{kN} \mathrm{m}^{-2}$ under the low and high shear rate (Fig. 4b), while such reduction in friction coefficient in the YDG sample is only about $4.1 \%$ and $4.8 \%$ (Fig. 5b). Furthermore, under the low and high shear rate, the friction coefficient reduction in DBZ samples is only approximately $5.6 \%$ and $6.0 \%$ (Fig. 6b). Skempton (1985) reported that the strength of soils falls to the residual value in ring shear tests, owing to reorientation of platy clay minerals parallel to the direction of shearing. Based on the conclusion that the postpeak drop in strength of normally consolidated soil is only due to particle reorientation after the peak strength (Skepmton, 1964; Mesri and Shahien, 2003; Habibbeygi and Nikraz, 2018), the results demonstrated that the DJG landslide soil exhibited a greater particle reorientation compared with that of the other two landslide soils.

\subsection{Effect of normal stress on the friction coefficients}

It can be seen from the Figs. 4b-6b that the friction coefficients (peak and residual) are higher at low effective normal stress levels (effective normal stress equal to or less than $100 \mathrm{kN} \mathrm{m}^{-2}$ ) compared with those at high normal stress (effective normal stress between 200 and $400 \mathrm{kN} \mathrm{m}^{-2}$ ). For example, with normal stress increasing from 100 to $400 \mathrm{kN} \mathrm{m}^{-2}$, the peak and residual friction coefficients of DJG landslide soils at a shear rate of $0.1 \mathrm{~mm} \mathrm{~min}^{-1}$ reduce from 0.569 to 0.32 and from 0.3 to 0.262 (Fig. $4 \mathrm{~b}$ ), respectively. Similarly, results obtained from the other two landslide loesses also show that the friction coefficients decrease nonlinearly with normal stresses (Figs. 5b and 6b). Furthermore, specimens with a shear rate of $0.1 \mathrm{~mm} \mathrm{~min}^{-1}$ attained greater friction coefficients than those with a shear rate of $1 \mathrm{~mm} \mathrm{~min}^{-1}$ (Figs. 4b-6b).

\subsection{Effects of shear rate on residual strength parameter}

Following the previous study reported by Eid et al. (2019) and Terzaghi et al. (1996), the maximum value during the shear process can be the peak shear stress, whereas the minimum value can be the minimum shear stress. Correspondingly, the maximum value can be referred to as the peak shear strength, whereas the minimum value can be referred to as the residual shear strength that resulted from particle rearrangements after a large shear displacement. Furthermore, the peak and residual strength parameters are determined by using the Mohr-Coulomb failure criterion (Terzaghi et al., 1996). In this study, the residual strength parameters were analyzed and discussed.

For the samples described above, Figs. 8-10 show the residual friction coefficient-normal stress relationship as well as the residual strength parameters. The residual friction coefficient is plotted against the normal stress. The residual 

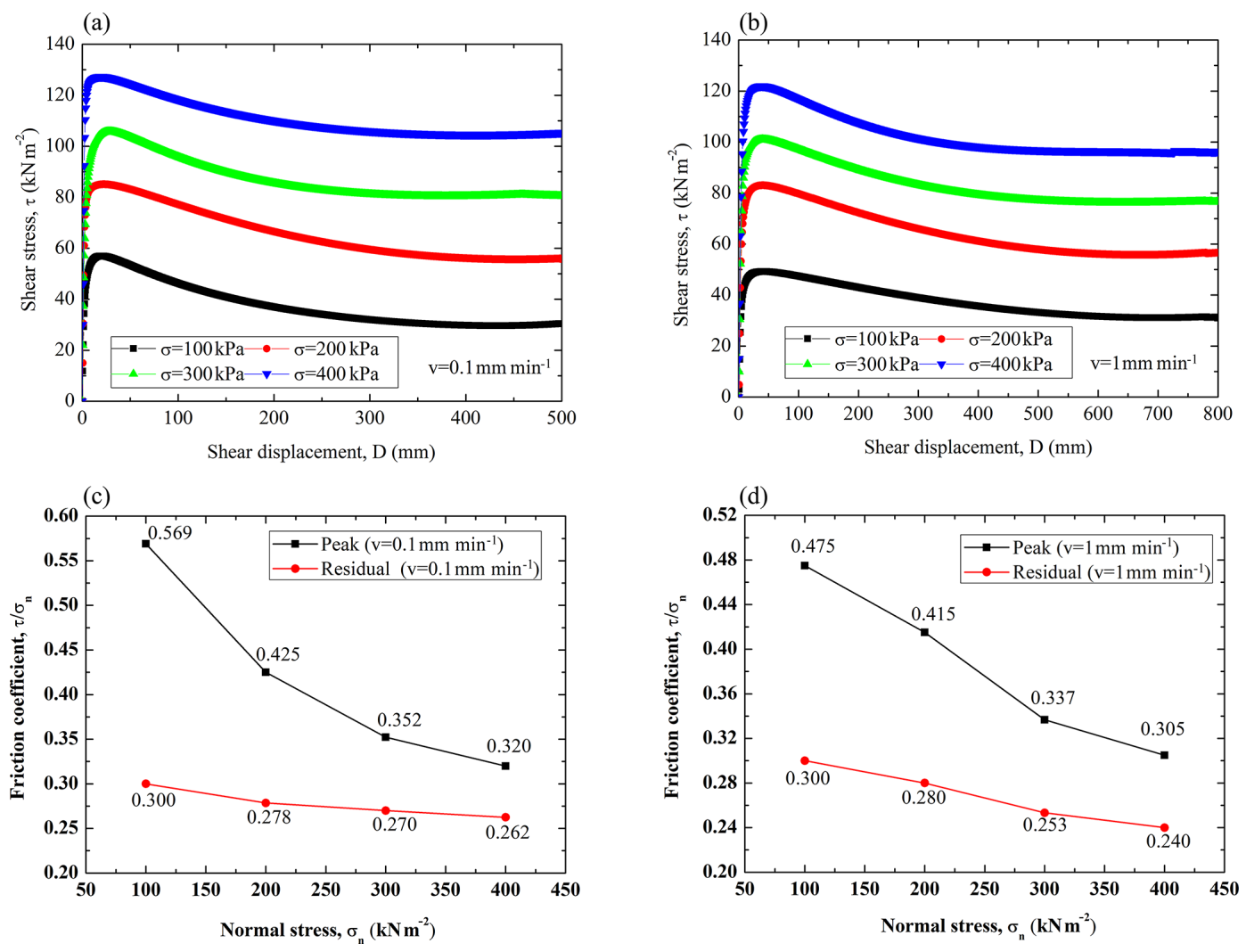

Figure 4. Shear behavior characteristics of DJG soil samples. (a) Relationship between shear stress and shear displacement. (b) Relationship between friction coefficient and normal stress.

friction coefficient is defined as the residual shear strength divided by normal stress. It has been recognized that the shear strength parameters include cohesion and friction angle (Terzaghi, 1951; Stark Timothy et al., 2005; Pakbaz et al., 2018). However, according to the previous studies, the residual angle of soils varies depending on the soil properties as well as the magnitude of normal stress provided the residual cohesion of soil is zero (Kimura et al., 2014; Skempton, 1964). Thus, in this study, the residual frictions are calculated by Coulomb's law assuming the residual cohesion is 0 following the previous studies (Skempton, 1985). The residual strength parameters were defined as $\phi_{\mathrm{r}}(0.1)$ and $\phi_{\mathrm{r}}(1)$ at the low shear rate and high shear rate, respectively. And the difference between the residual friction angles at two shear rates was defined as $\phi_{\mathrm{r}}(1)-\phi_{\mathrm{r}}(0.1)$. Comparatively, the residual friction coefficient was defined as $\tau_{\mathrm{r}} / \sigma_{n}(0.1)$ at the low shear rate and $\tau_{\mathrm{r}} / \sigma_{n}(1)$ at the high shear rate, respectively. Furthermore, the difference between the residual friction coefficients was defined as $\tau_{\mathrm{r}} / \sigma_{n}(1)-\tau_{\mathrm{r}} / \sigma_{n}(0.1)$. Table 2 summarized the residual shear parameters of the landslide soils.

Figure 8 shows that the residual friction coefficients are relatively low in DJG samples. The coefficients $\tau_{\mathrm{r}} / \sigma_{n}(0.1)$ and $\tau_{\mathrm{r}} / \sigma_{n}(1)$ at a normal stress of 100 to $400 \mathrm{kN} \mathrm{m}^{-2}$ ranged from 0.3 to 0.262 and from 0.3 to 0.24 , respectively. The difference between the friction coefficients, $\tau_{\mathrm{r}} / \sigma_{n}(1)-$ $\tau_{\mathrm{r}} / \sigma_{n}(0.1)$, at each normal stress level is varied in a range of -0.022 to +0.002 . The difference between the residual friction angles, $\phi_{\mathrm{r}}(1)-\phi_{\mathrm{r}}(0.1)$, ranged from -1.212 to $+0.079^{\circ}$ (Table 2). For normal stress above $200 \mathrm{kN} \mathrm{m}^{-2}$, the residual friction coefficient $\tau_{\mathrm{r}} / \sigma_{n}(0.1)$ was found to be greater than the residual friction coefficient $\tau_{\mathrm{r}} / \sigma_{n}(1)$. For this sample, residual friction coefficients show a slight decrease with the shear rate for normal stress above $200 \mathrm{kN} \mathrm{m}^{-2}$.

Figure 9 gives the results of the YDG samples. The coefficients $\tau_{\mathrm{r}} / \sigma_{n}(0.1)$ and $\tau_{\mathrm{r}} / \sigma_{n}(1)$ under a normal stress of 100 to $400 \mathrm{kN} \mathrm{m}^{-2}$ ranged from 0.57 to 0.52 and from 0.52 to 0.50 , respectively. Furthermore, the difference $\tau_{\mathrm{r}} / \sigma_{n}(1)-$ $\tau_{\mathrm{r}} / \sigma_{n}(0.1)$ at each normal stress was from -0.05 to -0.02 . The difference between the residual friction angles, $\phi_{\mathrm{r}}(1)-$ $\phi_{\mathrm{r}}(0.1)$, was in the range of -2.218 to $-0.909^{\circ}$. In the case of the YDG soil sample, the residual friction coefficients decreased with an increase in shear rate for all normal stress levels.

Figure 10 presents the results of the DBZ samples. The coefficients $\tau_{\mathrm{r}} / \sigma_{n}(0.1)$ and $\tau_{\mathrm{r}} / \sigma_{n}(1)$ at a normal stress of 100 to $400 \mathrm{kN} \mathrm{m}^{-2}$ ranged from 0.8 to 0.625 and from 0.76 to 0.613 , respectively. The difference $\tau_{\mathrm{r}} / \sigma_{n}(1)-\tau_{\mathrm{r}} / \sigma_{n}(0.1)$ at each normal stress was from -0.04 to -0.01 . The difference $\phi_{\mathrm{r}}(1)-\phi_{\mathrm{r}}(0.1)$ was from -1.425 to $-0.405^{\circ}$. For DBZ samples, there was a slight decreasing tendency of the residual 

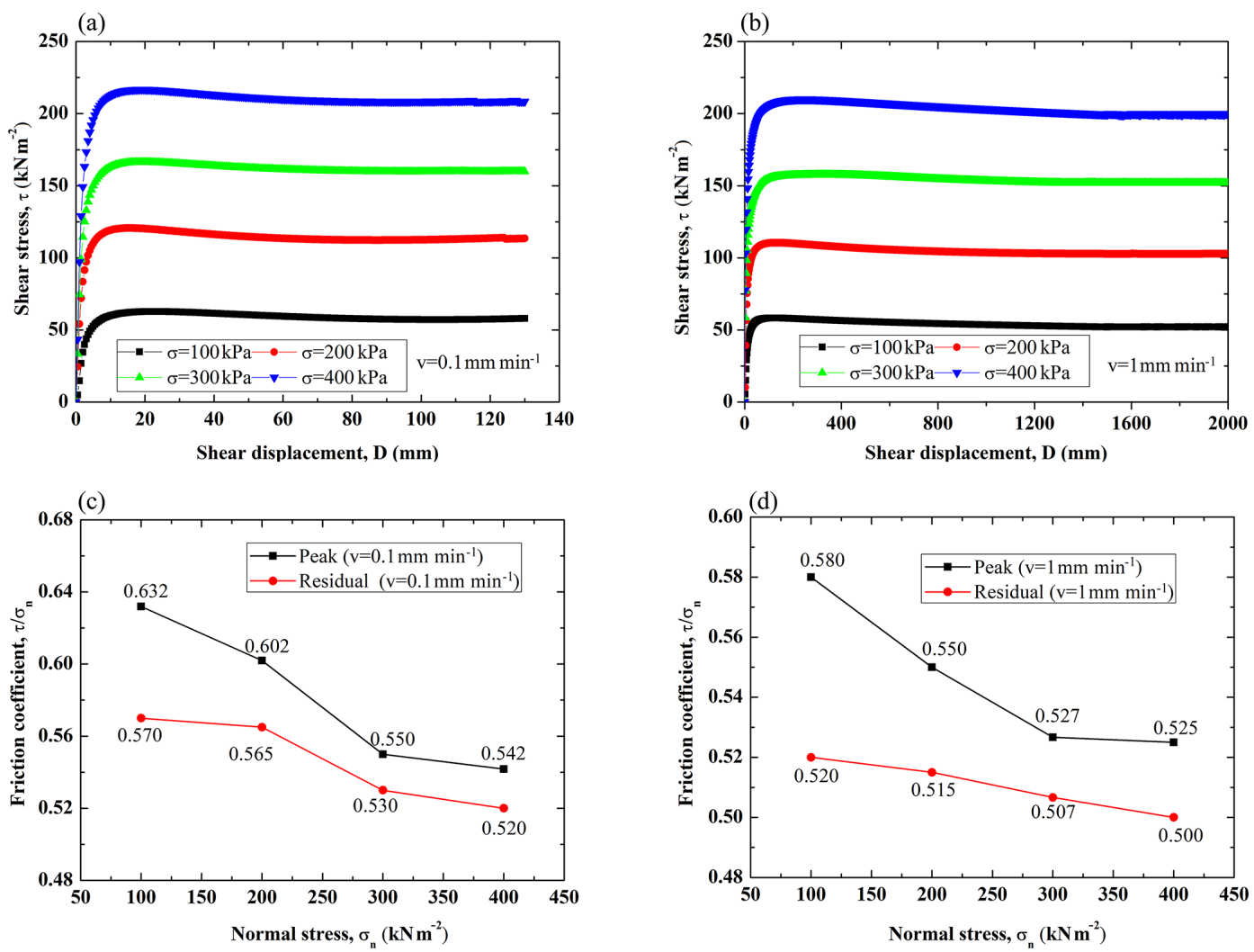

Figure 5. Shear behavior characteristics of YDG soil samples. (a) Relationship between shear stress and shear displacement. (b) Relationship between friction coefficient and normal stress.

friction coefficients with increasing shear rate for all normal stress levels. It is noted that the maximum difference was found at the lowest normal stress of $100 \mathrm{kN} \mathrm{m}^{-2}$.

From the experimental results of the three selected landslides, it was found that there is a negative relationship between residual friction coefficients and shear rates for all samples (Figs. 8-10). Such a negative effect of shear rate (higher residual friction coefficients at lower rates) has been reported in the literature for fine-grained soils (Gratchev Ivan and Sassa, 2015; Tika et al., 1996). This effect may be closely associated with the ability of clay particles in a specimen to restore broken bonds at different shear rates. Previous scholars concluded that with higher shear rates, the breakdown of the bonds between clay particles or flocs exceeds the restoration bond, leading to a reduction in residual friction coefficients (Osipov et al., 1984; Perret et al., 1996). In contrast, the bonds between particles are rebuilt quickly, and the recovery rate can catch up to the breakdown rate at lower shear rates. Therefore, the weaker bonding between particles could explain the strength drop with increasing shear rate in this study.

As for YDG and DBZ specimens, it is found that the shear rate effect on the friction coefficient can be seen to decrease with normal stress (Figs. 9-10). By contrast, there is an increasing tendency in the influence of shear rate on the friction coefficient with normal stress in the DJG specimen (Fig. 8). Gibo et al. (1987) reported that the residual friction angle of soils was controlled by the effective normal stress as well as by the clay fraction (CF). Interestingly, YDG (with a CF of $9 \%$ ) and DBZ (with a CF of 9.1\%) specimens with almost the same fraction of clay showed a similar shear rate effect on the residual friction coefficient, with normal stress increasing; however, DJG (with a CF of $24 \%$ ) showed a contrasting tendency of shear rate effect on residual friction coefficient with normal stress, indicating that such an effect is closely associated with $\mathrm{CF}$.

Table 2 summarizes residual strength parameters including $\phi_{\mathrm{r}}(0.1)$ and $\phi_{\mathrm{r}}(1)$ of all specimens obtained from the ring shear tests in this study. As for the DJG samples, the residual strength parameters $\phi_{\mathrm{r}}(0.1)$ and $\phi_{\mathrm{r}}(1)$ for all normal stresses were found to be $15.003^{\circ}$ and $14.09^{\circ}$ (Fig. 8), respectively. However, the residual friction angles $\phi_{\mathrm{r}}(0.1)$ and $\phi_{\mathrm{r}}(1)$ of the YDG samples were obtained to be $27.954^{\circ}$ and $26.778^{\circ}$ (Fig. 9), respectively. In the case of the DBZ sample, the friction angles $\phi_{\mathrm{r}}(0.1)$ and $\phi_{\mathrm{r}}(1)$ were high, $32.822^{\circ}$ and $32.293^{\circ}$ (Fig. 10), respectively. The residual friction angles $\phi_{\mathrm{r}}(0.1)$ and $\phi_{\mathrm{r}}(1)$ under all normal stresses were from $15.003^{\circ}$ to $32.822^{\circ}$ and from $14.09^{\circ}$ to $32.293^{\circ}$, respectively.

Due to the influence of the shear rate, the difference $\phi_{\mathrm{r}}(1)-\phi_{\mathrm{r}}(0.1)$ at each normal stress level varies in different 

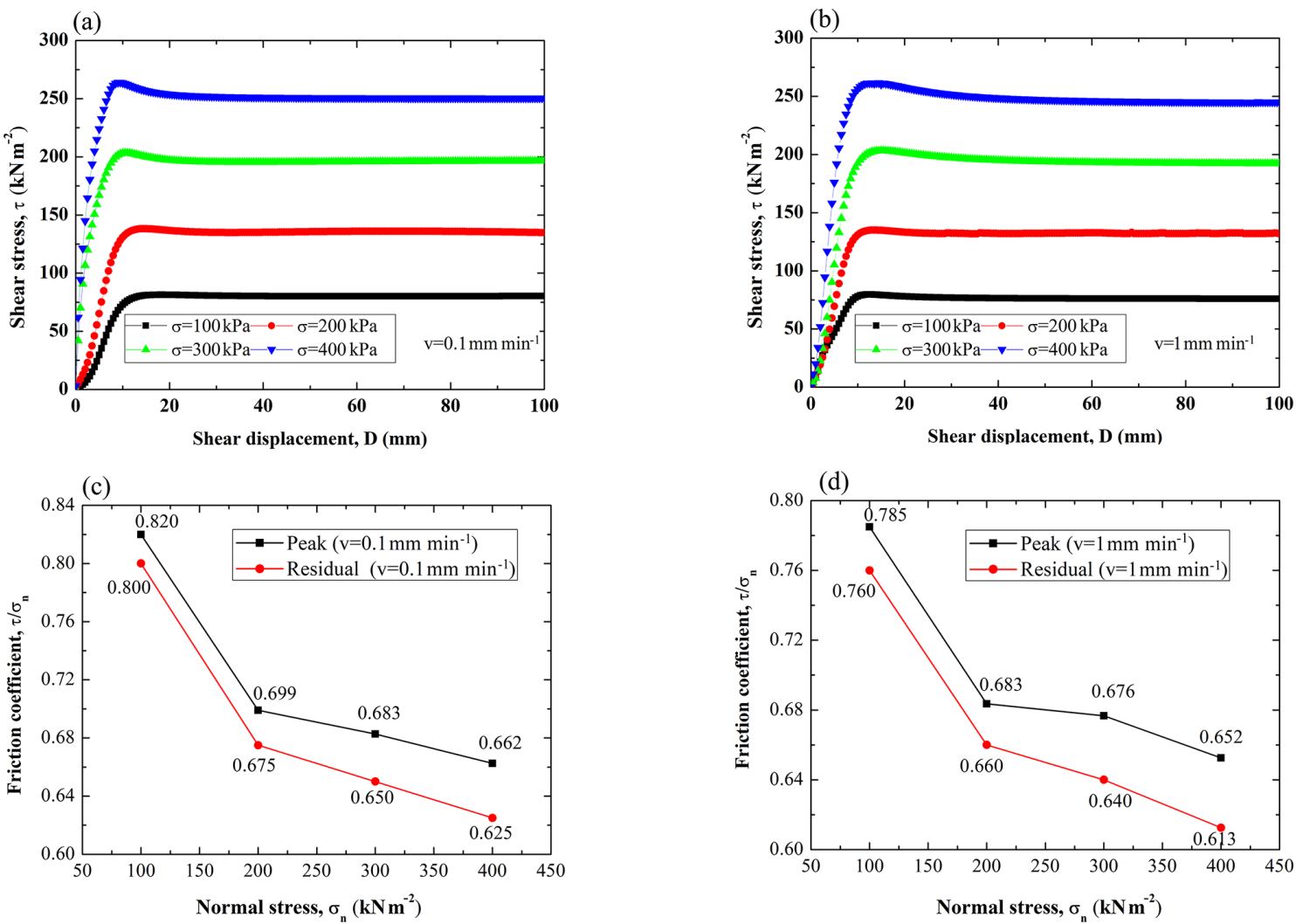

Figure 6. Shear behavior characteristics of the DBZ soil samples. (a) Relationship between shear stress and shear displacement. (b) Relationship between friction coefficient and normal stress.
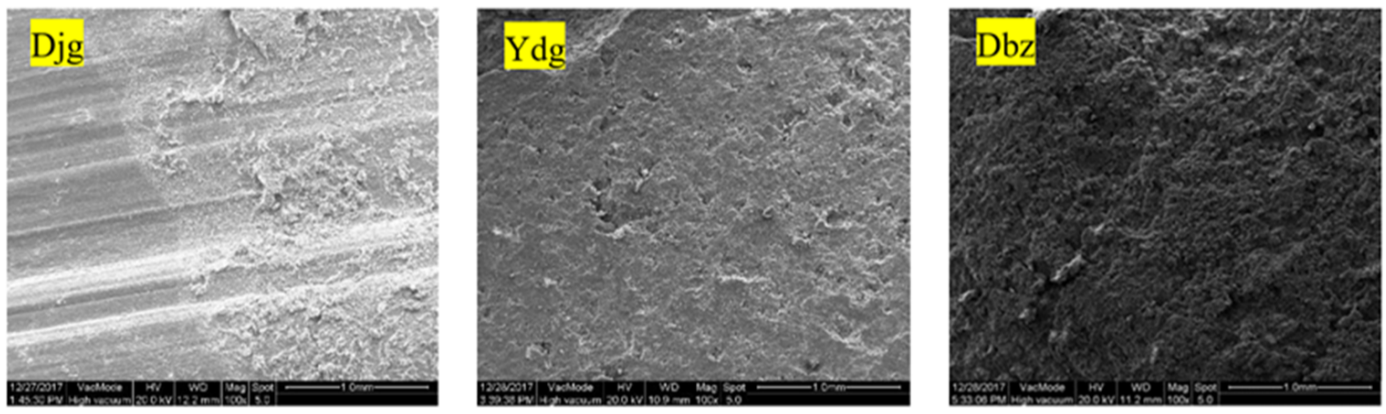

Figure 7. Scanning electron microscope (SEM) photographs of the shear surface of loess samples (100 magnification).

locations, while the values of $\phi_{\mathrm{r}}(1)-\phi_{\mathrm{r}}(0.1)$ under all normal stresses for the DJG, YDG and DBZ samples were -0.913, -1.176 and $-0.529^{\circ}$, respectively (Table 2). Wang (2014) and Fan et al. (2017) asserted that the residual shear strength of the remolded loess was hardly affected by shear rates below $5 \mathrm{~mm} \mathrm{~min}^{-1}$. However, the results in this study show that $\phi_{\mathrm{r}}(1)-\phi_{\mathrm{r}}(0.1)$ under all normal stress levels is negative for loess. Moreover, the absolute value of $\phi_{\mathrm{r}}(1)-\phi_{\mathrm{r}}(0.1)$ in YDG samples even reached up to $1.176^{\circ}$. Therefore, the ring shear test results provide a basis for some general comments on the use of test results with different shear rates, partially deepening some aspects derived from previous studies.

\subsection{Influence of the shear rate on the residual friction angles according to soil properties}

It has been recognized that residual shear strength of soils is closely related to soil properties, such as particle size distribution (PSD), liquid limit (LL), plasticity index (IP) and clay fraction (CF; Terzaghi et al., 1996; Sayyah et al., 2016; $\mathrm{Xu}$ et al., 2018; Eid et al., 2016). Figure 11 depicts the relationships between residual friction angles as well as the difference in the residual friction angles and soil properties, including LL, IP and CF at two shear rates. The residual friction angles at two shear rates decreased nonlinearly with in- 

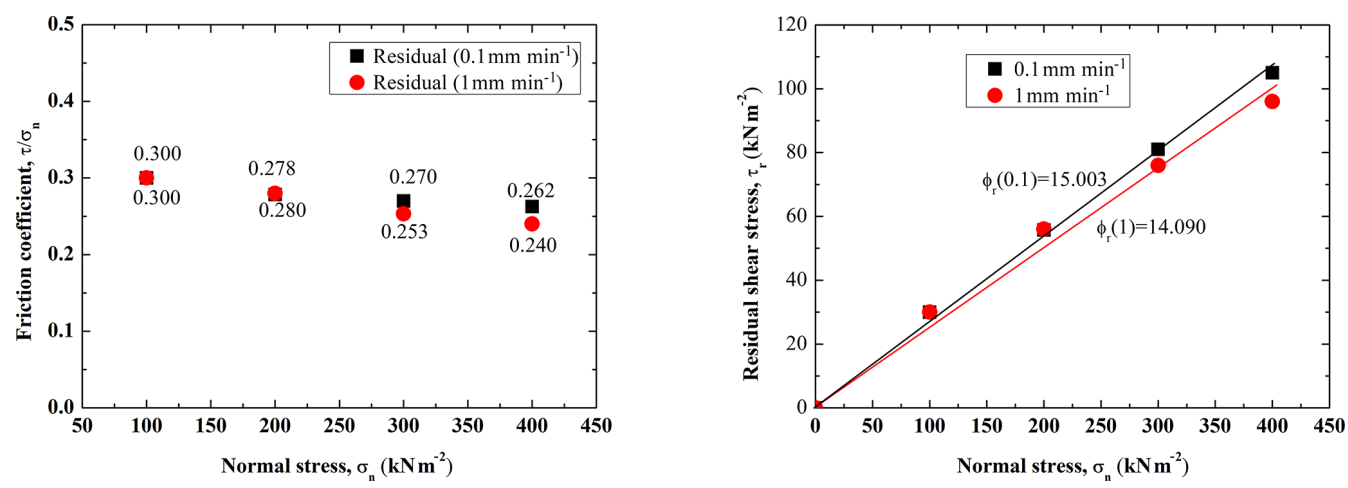

Figure 8. Relationships between residual shear stress and normal stress, and residual strength parameter for DJG soil sample.
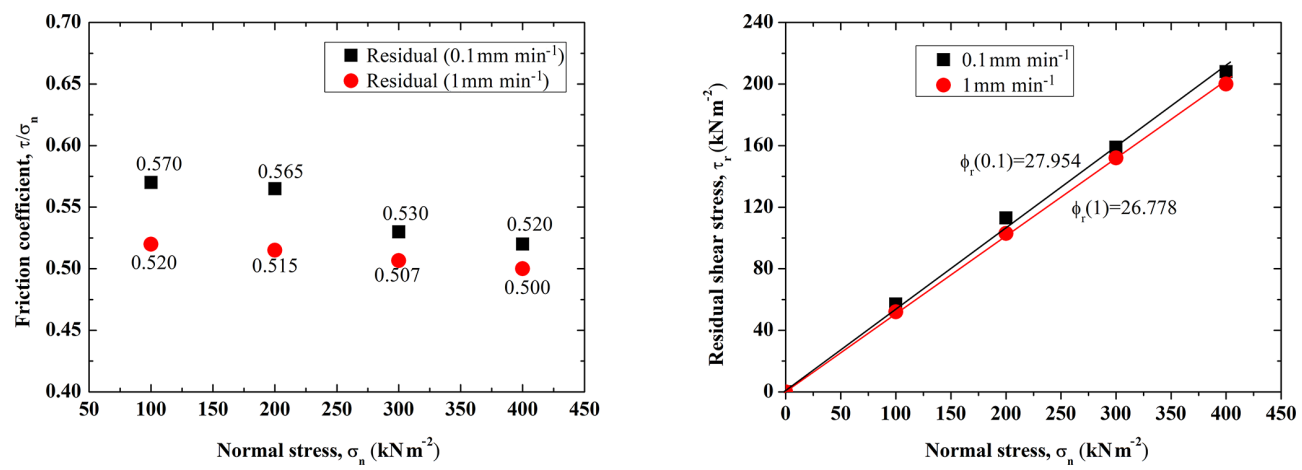

Figure 9. Relationships between residual shear stress and normal stress, and residual strength parameter for YDG soil samples.

creasing LL. As for the relationship between the $\phi_{\mathrm{r}}$ and IP, the $\phi_{\mathrm{r}}$ under low and high shear rates decreases from about $32^{\circ}$ to $15^{\circ}$ when IP increases from 11 to 16 . These findings agree well with early studies (Wesley, 2003; Tiwari et al., 2005). When CF increases from $9 \%$ to $24 \%$, the residual friction angles under low and high shear rates were found to decrease (Fig. 11). These observations are consistent with previous studies (Lupini et al., 1981; Gibo et al., 1987). Interestingly, for DBZ and YDG soils, which have similar percentage of clay fraction, the residual friction angles at both shear rates varied. However, in the relationships between the difference in the residual friction angles and the soil properties, no clear correlations were found.

\section{Conclusions}

A series of ring shear tests were conducted on loess obtained from three landslides to study the residual shear characteristics of saturated loess. Based on the test results, the effect of the shear rate on the residual shear characteristics of loess in a naturally drained condition was examined. The following conclusions can be drawn:

1. The ring shear test revealed that (i) shear displacement to achieve the residual stage with a high shear rate is greater than that of the low shear rate, (ii) both the peak and residual friction coefficients became smaller with an increase in shear rate for each sample, and (iii) the greater difference between the peak and the residual friction coefficient in loess samples could be attributed to relatively well-developed slickenside on the shear surface.

2. At the two shear rates, there was a nonlinearly decreasing trend of the residual friction coefficient with the normal stress in all loess samples. The difference between the friction coefficients, $\tau_{\mathrm{r}} / \sigma_{n}(1)-\tau_{\mathrm{r}} / \sigma_{n}(0.1)$, was found to decrease with normal stress in YDG and DBZ specimens, while it increases with normal stress in DJG specimens, indicating that CF may be closely associated with the shear rate effect on residual friction coefficient with normal stress. Therefore, as for YDG and DBZ with a relatively low fraction of CF, there is an increasing effect of shear rate on residual friction coefficient with decreasing normal stress. Thus, for the application of measured residual friction coefficient for stability analysis of shallow landslides with lower overburden pressure, it is significant for us to use a low shear rate in ring shear tests to measure residual shear strength parameters. On the other hand, for DJG with high CF, it is more reliable to use a low shear rate in ring shear tests to determine the residual friction coefficient for stability 

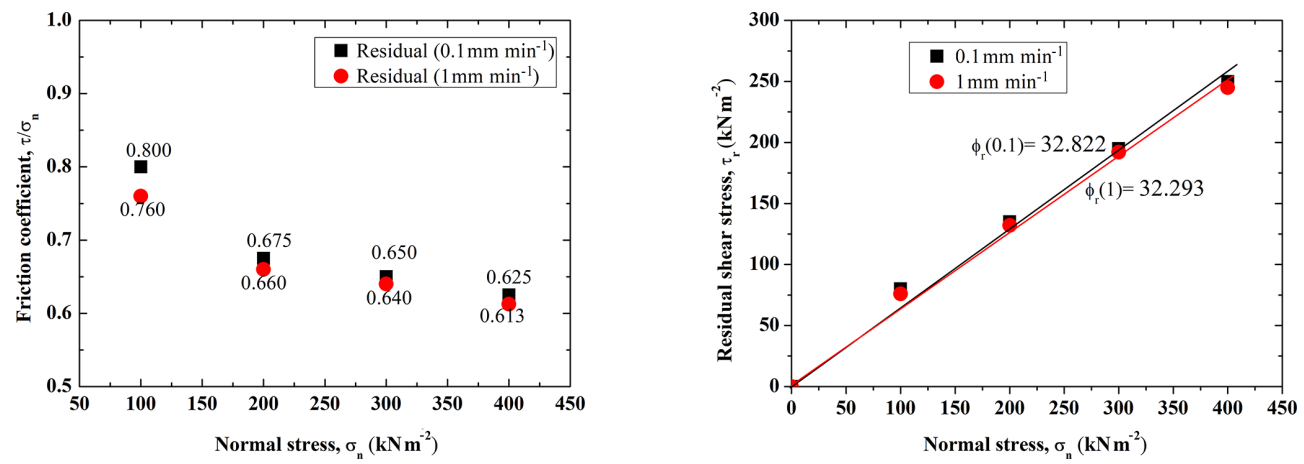

Figure 10. Relationships between residual shear stress and normal stress and residual strength parameter for the DBZ soil sample.
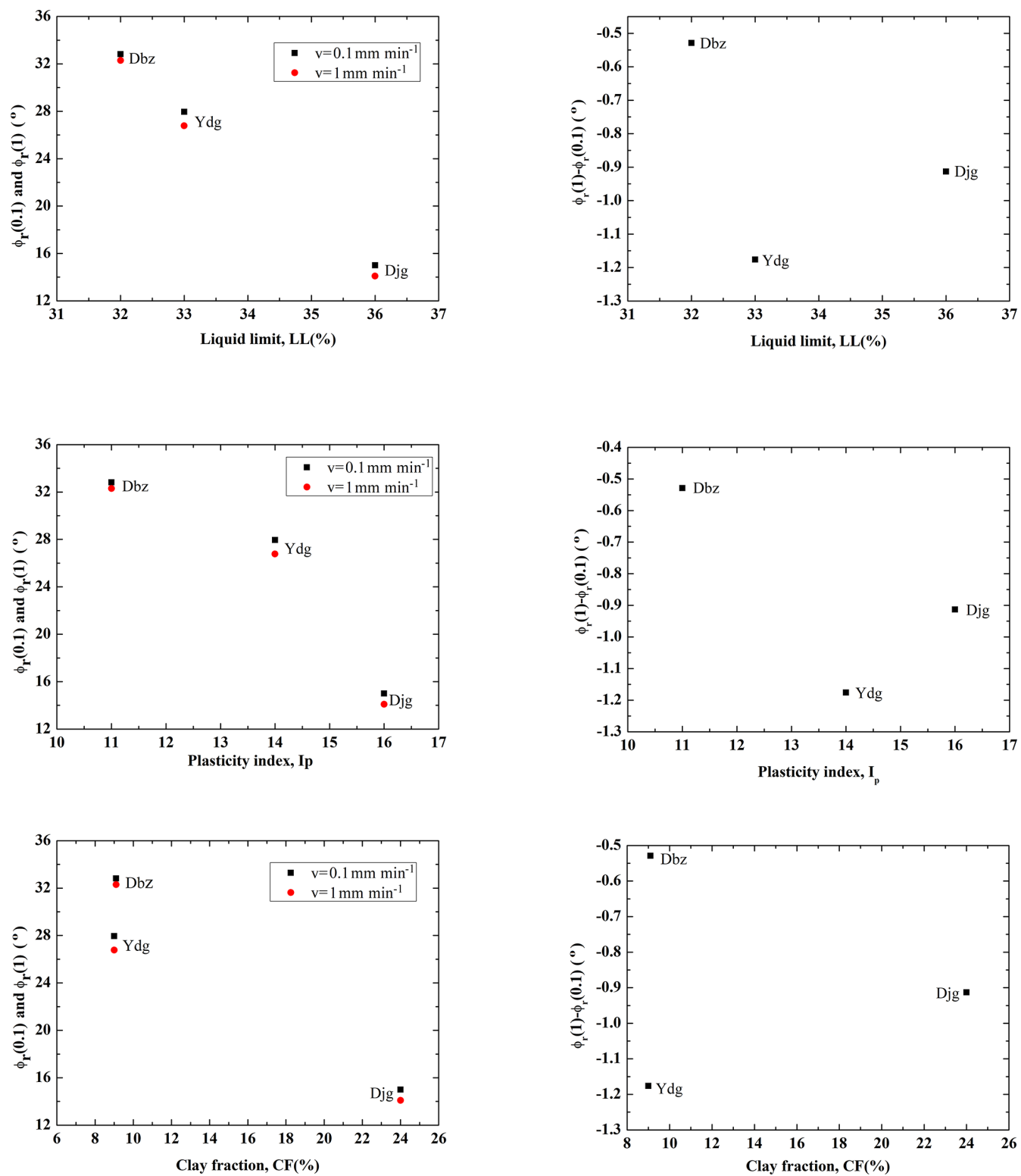

Figure 11. Relationships between residual shear parameter, the difference in residual shear parameter and the soil properties at two shear rates. 
analysis of deep landslides with high overburden pressure.

3. The difference at the two shear rates, $\phi_{\mathrm{r}}(1)-\phi_{\mathrm{r}}(0.1)$, under each normal stress level was either negative or positive. However, under all normal stress levels, the difference at the two shear rates $\phi_{\mathrm{r}}(1)-\phi_{\mathrm{r}}(0.1)$ was found to be negative. Such negative shear rate effect on loess could be attributed to greater ability of clay particles in specimen to restore broken bonds at low shear rates.

4. The relationships between the $\phi_{\mathrm{r}}$ under two shear rates and soil properties (LL, IP) demonstrated that the $\phi_{\mathrm{r}}$ at both shear rates decreased gradually with increasing LL and IP. However, no clear correlations between the difference in the $\phi_{\mathrm{r}}$ at low and high shear rates and the soil properties were found.

A first attempt was made in this work to describe some shear rate effect on the residual characteristics of the saturated loess. The obtained experimental results do suggest that the residual shear behavior of saturated loess can be affected, to a certain extent, by the shear rate. However, a more quantitative evaluation of such effects and a deeper understanding of the underlying processes must be achieved in order to assess their role in the initiation and mobility of loess landslides.

Code availability. Code can be made available by the authors upon request.

Data availability. Data can be made available by the authors upon request.

Author contributions. BL, XW, JP and QH conceived and designed the method; BL produced the results and wrote the original manuscript under the supervision of XW and JP. JP and QH reviewed the writing and edited the manuscript.

Competing interests. The authors declare that they have no conflict of interest.

Acknowledgements. This research was supported by the Major Program of the National Natural Science Foundation of China (grant no 41790440), the National Natural Science Foundation of China (no. 41902268) and the China Postdoctoral Science Foundation (grant no. 2019T120871). We thank the editor Mario Parise and the anonymous reviewers for their constructive comments, which helped us improve the quality of the paper.

Financial support. This research has been supported by the Major Program of the National Natural Science Foundation of China (grant no. 41790440), the National Natural Science Foundation of China (no. 41902268) and the China Postdoctoral Science Foundation (grant no. 2019T120871).

Review statement. This paper was edited by Mario Parise and reviewed by two anonymous referees.

\section{References}

Ajmera, B., Tiwari, B., and Shrestha, D.: Effect of mineral composition and shearing rates on the undrained shear strength of expansive clays, in: GeoCongress 2012: State of the Art and Practice in Geotechnical Engineering, Proceedings of GeoCongress 2012, Oakland, CA, USA, 25-29 March 2012, 1185-1194, 2012.

ASTM: ASTM D422-63: Standard Test Method for Particle-Size Analysis of Soils, ASTM International, West Conshohocken, PA, USA, 2007.

Bhat, D. R.: Effect of shearing rate on residual strength of kaolin clay, $\mathrm{PhD}$ thesis, Graduate school of Science and Engineering, Ehime University, Japan, 2013.

Bishop, A. W., Green, G. E., Garga, V. K., Andresen, A., and Brown, J. D.: A new ring shear apparatus and its application to the measurement of residual strength, Geotechnique, 21, 273328, 1971.

Bromhead, E.: The stability of slopes, blackie academic and professional, CRC Press, London, UK, 1992.

Chen, X., and Liu, D.: Residual strength of slip zone soils, Landslides, 11, 305-314, 2013.

Dijkstra, T., Rogers, C., Smalley, I., Derbyshire, E., Li, Y. J., and Meng, X. M.: The loess of north-central China: geotechnical properties and their relation to slope stability, Eng. Geol., 36, 153-171, 1994.

Ding, H.: Ring shear tests on strength properties of loess in different regions (in Chinese), Master thesis, Northwest A\&F University, Shaanxi, China, 2016.

Eid, H. T.: Stability charts for uniform slopes in soils with nonlinear failure envelopes, Eng. Geol., 168, 38-45, 2014.

Eid, H. T., Rabie, K. H., and Wijewickreme, D.: Drained residual shear strength at effective normal stresses relevant to soil slope stability analyses, Eng. Geol., 204, 94-107, 2016.

Eid, H. T., Al-Nohmi, N. M., Wijewickreme, D., and Amarasinghe, R. S.: Drained Peak and Residual Interface Shear Strengths of Fine-Grained Soils for Pipeline Geotechnics, J. Geotech. Geoenviron., 145(10), 06019010, https://doi.org/10.1061/(ASCE)GT.1943-5606.0002131, 2019.

Fan, X., Xu, Q., Scaringi, G., Li, S., and Peng, D.: A chemomechanical insight into the failure mechanism of frequently occurred landslides in the Loess Plateau, Gansu Province, China, Eng. Geol., 228, 337-345, 2017.

Gibo, S., Gashira, K., and Ohtsubo, M.: Residual strength of smectite-dominated soils from the Kamenose landslide in Japan, Can. Geotech. J., 24, 456-462, 1987.

Gratchev Ivan, B., and Sassa, K.: Shear strength of clay at different shear rates, J. Geotech. Geoenviron., 141(5), 06015002, https://doi.org/10.1061/(asce)gt.1943-5606.0001297, 2015. 
Grelle, G., and Guadagno, F. M.: Shear mechanisms and viscoplastic effects during impulsive shearing, Geotechnique 41, 91-103, 2010.

Habibbeygi, F., and Nikraz, H.: Effect of shear rate on the residual shear strength of pre-sheared clays, Cogent Geoscience, 4, 1-9, 2018.

Hu, S., Qiu, H., Wang, X., Gao, Y., Wang, N., Wu, J., Yang, D., and Cao, M.: Acquiring high-resolution topography and performing spatial analysis of loess landslides by using low-cost UAVs, Landslides, 15, 593-612, 2018.

Kimura, S., Nakamura, S., Vithana, S. B., and Sakai, K.: Shearing rate effect on residual strength of landslide soils in the slow rate range, Landslides, 11, 969-979, https://doi.org/10.1007/s10346013-0457-6, 2014.

Kimura, S., Nakamura, S., and Vithana, S. B.: Influence of effective normal stress in the measurement of fully softened strength in different origin landslide soils, Soil Till. Res., 145, 47-54, 2015.

Kramer, S., Wang, C., and Byers, M.: Experimental measurement of the residual strength of particulate materials, Physics and Mechanics of Soil Liquefaction, 249-260, 1999.

Lemos, L.: Earthquake loading of shear surfaces in slopes, Proceedings of the 11th international conference on soil mechanics and foundation engineering, San Francisco, CA, USA, 12-16 August 1985, 4, 1955-1958, 1985.

Leng, Y., Peng, J., Wang, Q., Meng, Z., and Huang, W.: A fluidized landslide occurred in the Loess Plateau: A study on loess landslide in South Jingyang tableland, Eng. Geol., 236, 129-136, 2018.

Li, D., Yin, K., Glade, T., and Leo, C.: Effect of over-consolidation and shear rate on the residual strength of soils of silty sand in the Three Gorges Reservoir, Sci. Rep., 7, 1-11, 2017.

Li, Y. R., Wen, B. P., Aydin, A., and Ju, N. P.: Ring shear tests on slip zone soils of three giant landslides in the Three Gorges Project area, Eng. Geol., 154, 106-115, 2013.

Lupini, J. F., Skinner, A. E., and Vaughan, P. R.: The drained residual strength of cohesive soils, Geotechnique, 31, 181-213, 1981.

Ma, P., Peng, J., Wang, Q., Zhuang, J., and Zhang, F.: The mechanisms of a loess landslide triggered by diversion-based irrigation: a case study of the South Jingyang Platform, China, B. Eng. Geol. Environ., 78, 4945-4963, 2019.

Mesri, G. and Shahien, M.: Residual shear strength mobilized in first-time slope failures, J. Geotech. Geoenviron., 129, 12-31, 2003.

Moeyersons, J., Van Den Eeckhaut, M., Nyssen, J., Gebreyohannes, T., Van de Wauw, J., Hofmeister, J., Poesen, J., Deckers, J., and Mitiku, H.: Mass movement mapping for geomorphological understanding and sustainable development: Tigray, Ethiopia, Catena, 75, 45-54, 2008.

Morgenstern, N. R., and Hungr, O.: High Velocity ring shear tests on sand, Geotechnique, 34, 415-421, 1984.

Nakamura, S., Gibo, S., Egashira, K., and Kimura, S.: Platy layer silicate minerals for controlling residual strength in landslide soils of different origins and geology, Geology, 38, 743-746, 2010.

Okada, Y., Sassa, K., and Fukuoka, H.: Excess pore pressure and grain crushing of sands by means of undrained and naturally drained ring-shear tests, Eng. Geol., 75, 325-343, 2004.
Osipov, V., Nikolaeva, S., and Sokolov, V.: Microstructural changes associated with thixotropic phenomena in clay soils, Geotechnique, 34, 293-303, 1984.

Pakbaz, M., Behzadipour, H., and Ghezelbash, G.: Evaluation of shear strength parameters of sandy soils upon microbial treatment, Geomicrobiol. J., 35, 721-726, 2018.

Perret, D., Locat, J., and Martignoni, P.: Thixotropic behavior during shear of a fine-grained mud from Eastern Canada, Eng. Geol., 43, 31-44, 1996.

Picarelli, L.: Discussion on "A rapid loess flowslide triggered by irrigation in China" by D. Zhang, G. Wang, C. Luo, J. Chen, and Y. Zhou, Landslides, 7, 203-205, 2010.

Sassa, K., Fukuoka, H., Wang, G., and Ishikawa, N.: Undrained dynamic-loading ring-shear apparatus and its application to landslide dynamics, Landslides, 1, 7-19, 2004.

Sayyah, A., Eriksen, R. S., Horenstein, M. N., and Mazumder, M. K.: Performance analysis of electrodynamic screens based on residual particle size distribution, IEEE J. Photovolt., 7, 221-229, 2016.

She, X.: The formation mechanism of landslide of loess and bedrock contact surface (in Chinese), Master thesis, Chang'an University, Shaanxi, China, 2015.

Shinohara, K. and Golman, B.: Dynamic shear properties of particle mixture by rotational shear test, Powder Technol., 122, 255-258, 2002.

Skempton, A. W.: Long-term stability of clay slopes, Geotechnique, 14, 77-102, 1964.

Skempton, A. W.: Residual strength of clays in landslides, folded strata and the laboratory, Geotechnique, 35, 3-18, 1985.

Skepmton, A. W.: Long-term stability of clay slopes, Geotechnique, 14, 77-102, 1964.

Standardization Administration of China (SAC): China National Standards CNS-GB/T50123-1999, Standard for Soil Test Method, Ministry of Construction, Ministry of Water Resources, China Planning Press, Beijing, China, 1999.

Stark, T. D. and Vettel, J. J.: Bromhead ring shear test procedure, Geotech. Test. J., 15, 24-32, 1992.

Stark, T. D., Choi, H., and McCone, S.: Drained shear strength parameters for analysis of landslides, J. Geotech. Geoenviron., 131, 575-588, 2005.

Stark Timothy, D., Choi, H., and McCone, S.: Drained shear strength parameters for analysis of landslides, J. Geotech. Geoenviron., 131, 575-588, 2005.

Summa, V., Tateo, F., Giannossi, M., and Bonelli, C.: Influence of clay mineralogy on the stability of a landslide in Plio-Pleistocene clay sediments near Grassano (Southern Italy), Catena, 80, 75$85,2010$.

Summa, V., Margiotta, S., Medici, L., and Tateo, F.: Compositional characterization of fine sediments and circulating waters of landslides in the southern Apennines-Italy, Catena, 171, 199-211, 2018.

Sun, P., Peng, J., Chen, L., Yin, Y., and Wu, S.: Weak tensile characteristics of loess in China - An important reason for ground fissures, Eng. Geol., 108, 153-159, 2009.

Suzuki, M., Tsuzuki, S., and Yamamoto, T.: Residual strength characteristics of naturally and artificially cemented clays in reversal direct box shear test, Soils Found., 47, 1029-1044, 2007.

Terzaghi, K.: Theoretical soil mechanics, Chapman And Hall, Limited, London, UK, 1951. 
Terzaghi, K., Peck, R. B., and Mesri, G.: Soil mechanics in engineering practice, John Wiley \& Sons, New York, NY, USA, 1996.

Tika, T.: Ring shear tests on a carbonate sandy silt, Geotechn. Test. J., 22(4), 342-355, https://doi.org/10.1520/GTJ11248J, 1999.

Tika, T. E., Vaughan, P. R., and Lemos, L. J. L. J.: Fast shearing of pre-existing shear zones in soil, Geotechnique, 46, 197-233, 1996.

Tika, T. E. and Hutchinson, J. N.: Ring shear tests on soil from the Vaiont landslide slip surface, Geotechnique, 49, 59-74, 1999.

Tiwari, B.: Analysis of landslide mechanism of Okimi Landslide, M. Sc. Thesis, Niigata University, Niigata, Japan, 2000.

Tiwari, B., Brandon, T. L., Marui, H., and Tuladhar, G. R.: Comparison of residual shear strengths from back analysis and ring shear tests on undisturbed and remolded specimens, J. Geotech. Geoenviron., 131, 1071-1079, 2005.

Tiwari B., and Marui, H.: A new method for the correlation of residual shear strength of the soil with mineralogical composition, J. Geotech. Geoenviron., 131, 1139-1150, 2005.

Tiwari, G. and Latha, G. M.: Reliability analysis of jointed rock slope considering uncertainty in peak and residual strength parameters, B. Eng. Geol. Environ., 78, 913-930, 2019.

Vithana, S. B., Nakamura, S., Kimura, S., and Gibo, S.: Effects of overconsolidation ratios on the shear strength of remoulded slip surface soils in ring shear, Eng. Geol., 131-132, 29-36, 2012.

Wang, J., Li, P., Ma, Y., and Vanapalli, S. K.: Evolution of pore-size distribution of intact loess and remolded loess due to consolidation, J. Soils Sediments., 19, 1226-1238, 2019.
Wang, S., Wu, W., Xiang, W., and Liu, Q.: Shear behaviors of saturated loess in naturally drained ring-shear tests, in: Recent Advances in Modeling Landslides and Debris Flows, Springer, Cham, Switzerland, 19-27, 2015.

Wang, W.: Residual Strength of Remolded Loess in Ring Shear Tests, PhD thesis, Northwest A \& F University of China, Shaanxi, China, 2014.

Wesley, L.: Stability of slopes in residual soils, Obras y Proyectos, 10, 47-61, 2011.

Wesley, L. D.: Residual strength of clays and correlations using atterberg limits, Geotechnique, 23, 669-672, 2003.

Xu, C., Wang, X., Lu, X., Dai, F., and Jiao, S.: Experimental study of residual strength and the index of shear strength characteristics of clay soil, Eng. Geol., 233, 183-190, 2018.

Yan, G., Qi, F., Wei, L., Aigang, L., Yu, W., Jing, Y., Aifang, C., Yamin, W., Yubo, S., and Li, L.: Changes of daily climate extremes in Loess Plateau during 1960-2013, Quatern. Int., 371, 5-21, 2015.

Zhang, D., Wang, G., Luo, C., Chen, J., and Zhou, Y.: A rapid loess flowslide triggered by irrigation in China, Landslides, 6, 55-60, 2009.

Zhang, M., Jiao, P., and Wei, X.: Study on development characteristics and distribution regularity of landslide and geohazards in baota district, yan'an, Hydrogeology and Engineering Geology, 33, 72-74, 2006 (in Chinese). 